Chen, R. S. and R. W. Kates, 1994. "World Food Security: Prospects and Trends, " Thomas E.

Downing and Martin L. Parry, eds. Climate Change and World Food Security, a special issue of Food Policy Vol. 19 No.2, pp.192-208.

Food Policy 199419 (2) 192-208

\title{
World food security: prospects and trends
}

\author{
Robert S. Chen \\ Associate Director with the Interdisciplinary Data Resources Division of the \\ Consortium for International Earth Science Information Network (CIESIN), \\ 2250 Pierce Road, University Center, Michigan 48710, USA \\ Robert W. Kates \\ Independent Scholar (PO Box 8075, Trenton, Maine, USA) affiliated with \\ Brown University, Clark University and the College of the Atlantic
}

\begin{abstract}
A food-secure world produces enough food for its population and provides access to food for all its people. It must therefore ensure not only a balance between food availability and requirements, but also an end to famine, little seasonal or chronic undernutrition, and virtually no micronutrient deficiencies and nutrientdepleting illness. In 1990, we estimate that 15-35 million people were at risk of famine, 786 million were vulnerable to chronic undernutrition, and hundreds of millions suffered from micronutrient deficiencies, diarrhoea, measles, malaria, parasites, and other nutritional impairments. A normative scenario to achieve food security in the warmer, more crowded, more connected, but more diverse world of 2060 requires widespread acknowledgement of food as a human right, large increases in food production and income, a pervasive global safety net, and the capacity to cope with surprise. Some elements of these requirements are already in place. This normative scenario results in fewer than $\mathbf{1 0 0}$ million hungry people compared with other 'business as usual' scenarios that project a hungry population of 641 million in 2060 under current climate and 629-2087 million with climate change. Speculative and clearly optimistic, our normative scenario offers multiple pathways for achieving a food-secure world.
\end{abstract}

Keywords: food security, nutrient deficiencies, famine

Can we envision a food-secure world of the future, a world with food enough for all and all with access to food? Drawing upon interdisciplinary research on hunger, we identify four dimensions of hunger that should be absent in a food-secure world, dimensions that go beyond conventional measures of food security defined solely by the balance between food availability and food requirements. At a minimum, a food-secure world is a world without famine, with little seasonal or chronic undernutrition, and with virtually no micronutrient deficiencies and nutrientdepleting illness. Such a world would require broad acceptance of food as a basic human right, increased food availability far in excess of increased population, extensive growth in household income, a pervasive safety net of emergency assistance, entitlements, and special needs programmes, and a capability to adapt to the surprises of the future. We examine the likelihood of achieving such a 
food-secure world in 2060 by examining current trends and then comparing this world with two sets of scenarios of macroeconomic trends (with and without climate change). We conclude with a speculative agenda for thinking about how to attain the desired goal of food security in the world of 2060.

\section{Defining a food-secure world}

The standard definition of food security is 'access by all peoples at all times to enough food for an active, healthy life' (World Bank, 1986) but it is actually employed in different ways depending on the level of human organization.

At a regional or national level food security tends to be equated with the adequacy of the national food balance, the sufficiency of the available food supply to meet the food requirements of national populations. The degree of national food security is highly dependent on the minimal population nutritional requirements selected (in per capita dietary calories) and usually presumes equal access by all regions and social classes to the available supply over a time period of a year or more. The available supply is determined principally by the current level of food production and releases from food stocks within a country balanced by net food trade and aid flows, uses of food for purposes other than human consumption, and the carryover of food stocks from year to year. In this context, 'world' food security is most often perceived as the ability of all nations to achieve and maintain their own national food security.

At a household level, food security tends to be equated with the sufficiency of household entitlements - that bundle of food-production resources, income available for food purchases, and gifts or assistance sufficient to meet the aggregate food requirements of all household members - as inferred from surveys of income, food expenditures, and/or consumption. The degree of household food security also depends on the minimal nutritional requirements of individuals, on the time period of analysis selected, and the presumption that all households within common income or expenditure groups have the same entitlements to food, thus ignoring non-economic vulnerabilities. The available supply of food at the household level depends on a variety of factors including food markets and prices, transportation networks and storage facilities, weather and other environmental influences, and the form of food rationing, supplementation, and other entitlement programmes.

The concept of food security is least often employed at the level of individual household members. Individual food security implies an intake of food and absorption of nutrients sufficient to meet differential individual needs for activity, health, and growth and development. The level of need is determined primarily by an individual's age, gender, body size, health status, and level of physical activity. The availability of food to an individual is likely to depend on nutritional knowledge, occupation or lifestyle, and social, economic, and cultural relationships within and outside the household.

We believe that a food-secure world should provide security at all levels of human organization. As we look to the future, it is necessary to ask not only whether the world as a whole and its national components will be able to meet aggregate food needs, but also whether all households and individuals within nations can attain and maintain food security. This adds an important social dimension to what is otherwise often perceived as purely a competition between population growth, technological development, and environmental change. 


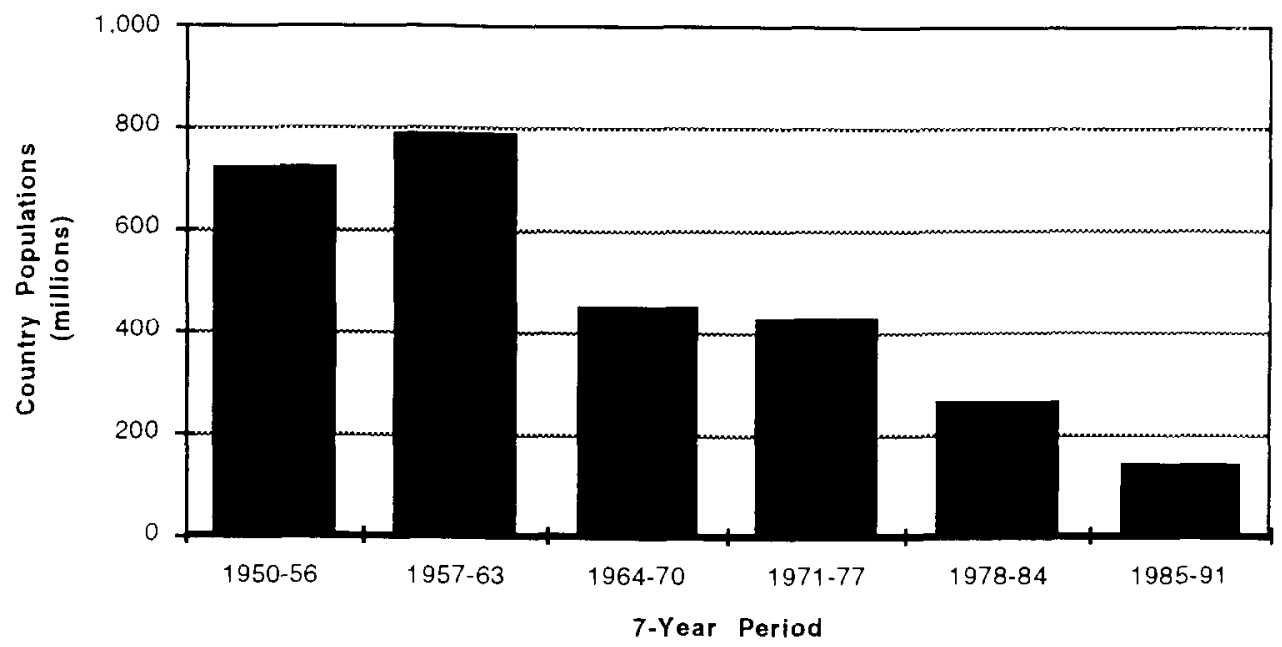

Figure 1 The FAMINDEX: Average total population of countries where famine was reported in The New York Times, 1950-91

\section{0: a food-insecure world}

The easiest way to observe food security is to examine its absence - the persistence of hunger in its many guises. Four aspects of hunger stand out as indicative of the overall prevalence of hunger and its future course: famine, undernutrition, micronutrient deficiencies, and nutrient-depleting illness. We begin with a review of the status of these four aspects circa 1990 and assess current trends.

\section{Famine}

For most people hunger is synonymous with famine. Famine is frequently associated with large and persistent food shortages, although we now know that people can suffer famine because of their inability to have access to food even when food is available (Sen, 1981). Indeed, most recent and ongoing famines (e.g., in Angola, Bosnia, Mozambique, Somalia and the Sudan) stem primarily from the use of hunger as a weapon in war through the appropriation, interdiction, or destruction of civilian food supplies. ${ }^{\prime}$

Despite the common perception that famine is now rampant, the number of people affected by famine as compared to other, less acute forms of hunger, is relatively small. Indeed, the trend in famines is clearly downward even though there are no good time series of famine mortality, morbidity, or even occurrence. To demonstrate this trend, we have used a simple indicator, the total population residing in countries where famine was reported in The New York Times, and we have constructed such a measure from 1950 onwards (Figure 1). ${ }^{2}$ Using this measure, the population affected directly or indirectly by famine in their country of

\footnotetext{
'Messer, E. 'Food wars: hunger as a weapon of war', The Hunger Report (1990); Chen, R. S. (ed.) Alan Shawn Feinstein World Hunger Program, Brown University, Providence, RI (1990), pp 27-35.

Kates, R. W., Chen, R. S., Downing, T. E., Kasperson, J. X., Messer, E. and Millman, S. R. The Hunger Report (1988); Alan Shawn Feinstein World Hunger Program, Brown University, Providence, RI, (1988); Kates, R W'Fnding deaths from famine: the opportunity in Somalia', New England.Journal of Medicine, 328, 14 (April 1993) pp 1055-1057.
} 
Table 1. Recent estimates of hunger

\begin{tabular}{|c|c|c|c|c|}
\hline Dimension of hunger/food security & $\begin{array}{l}\text { Population } \\
\text { (millions) }\end{array}$ & $\begin{array}{l}\text { Affected } \\
\text { (per cent) }\end{array}$ & Year & Source \\
\hline Famine (population at risk) & $15-35$ & $0.3-0.7$ & 1992 & WHP \\
\hline \multicolumn{5}{|l|}{ Undernutrition (chronic and seasonal) } \\
\hline FAO food poverty (1.2 BMR) & 477 & 9 & 1990 & WHP \\
\hline Updated FAO food poverty (1.54 BMR) & 786 & 20 & $1988-90$ & FAO \\
\hline Child malnutrition (weight below -2 s.d.) & 184 & 34 & 1990 & $\mathrm{ACC} / \mathrm{SCN}$ \\
\hline \multicolumn{5}{|l|}{ Micronutrient deficiencies } \\
\hline Iron deficiency (women 15-49) & 370 & 42 & $1980 \mathrm{~s}$ & ACCISCN \\
\hline Iodine deficiency & 211 & 5.6 & $1980 \mathrm{~s}$ & ACC/SCN \\
\hline Vitamin A deficiency (children $<5$ ) & 14 & 2.8 & $1980 \mathrm{~s}$ & $\mathrm{ACC} / \mathrm{SCN}$ \\
\hline \multicolumn{5}{|l|}{ Nutrient-depleting illness } \\
\hline $\begin{array}{l}\text { Diarrhoea, measles, malaria (deaths of } \\
\text { children }<5 \text { ) }\end{array}$ & 6.5 & 0.8 & $\sim 1990$ & UNICEF \\
\hline \multicolumn{5}{|l|}{ Parasites (infected population) ${ }^{\mathbf{n}}$} \\
\hline Giant roundworm & $785-1300$ & $15-25$ & $1980 \mathrm{~s}$ & World Bank \\
\hline Hookworm & $700-900$ & 13.17 & $1980 \mathrm{~s}$ & World Bank \\
\hline Whipworm & $500-750$ & $10-14$ & $1980 \mathrm{~s}$ & World Bank \\
\hline
\end{tabular}

${ }^{a}$ Includes those people expected to have multiple infections.

residence has declined greatly since the end of World War II, reflecting a lessening of the prevalence of famine and a major shift in famine incidence from populous Asia to less-populated Africa. Population in countries with reported famine peaked in the period $1957-63$ at a yearly average of almost 788 million, then declined to a yearly average of 264 million during 1978-84. This decline has continued over the seven years 1985-91, when the population of famine-plagued countries averaged 141 million. In 1992, The New York Times reported famine only in Somalia and the Sudan, which have a combined population of 35 million (Table 1).

Of course, these estimates based on national-level population surely overestimate the number of people directly subjected to famine, since famine conditions are almost always localized within countries, even in Somalia. At the same time, important pockets of famine may be readily overlooked by major news media. Based on an examination of actual reports of famine during the past three decades, we estimate that no more than 15-35 million people have been at risk of death due to famine in any given year.

\section{Undernutrition}

There are two widely used measures of undernutrition. The first is a measure of household access or 'food poverty', which is defined as the number of individuals living in households whose access to food as measured by income, expenditures, or consumption is insufficient to provide a dietary intake adequate for growth, activity, and good health. The United Nations Administrative Committee on Coordination-Subcommittee on Nutrition (ACC/SCN) estimates that, in 1990, 786 million people lived in households too poor to obtain the food they needed for health and modest levels of activity. ${ }^{3}$ A second measure of undernutrition is based on actual body measurements (anthropometry), which are closely linked to nutritional status. Sample surveys of children in developing countries indicate that

\footnotetext{
${ }^{3}$ The ACC/SCN estimates utilized a methodology recently updated by FAO which allows for a more consistent cutoff point for minimum average energy intake $(<1.54$ times the Basal Metabolic Rate at all ages) over the course of a year. This methodology produces higher estimates of food poverty than the earlier FAO methodology utilized by the IIASA study.
} 
in 1990,34 per cent of children under the age of five - about 184 million children had weights that fell two standard deviations or more below the mean of the international reference population. This represents a decrease from the 1975 ievel of 42 per cent, but due to rapid population growth the absolute number of undernourished children increased (from 168 million in 1975). Regionally, this indicator suggests that undernutrition has increased or remained static in Africa, decreased slowly in South Asia and Latin America, and declined rapidly in East and Southeast Asia.

\section{Micronutrient deficiencies}

Even when diets are adequate from the viewpoint of total food calories, they may be inadequate with respect to important micronutrients such as iron, iodine, and vitamin A. These micronutrient deficiencies affect hundreds of millions of people worldwide (see Table 1) and can lead to significant morbidy, long-term impairment and death. For example, about one billion people live in areas where diets tend to lack iodine, and more than 200 million people actually suffer from goitre. This condition is characterized by its distinctive swelling of the thyroid glands and often leads to lethargy and reduced mental function. Severe iodine deficiency in pregnant women can increase rates of miscarriage, stillbirth, congenital defects, foetal brain damage, low birth weight, and infant death. Severe deficiency in infants can cause brain damage and increased infant mortality. Iodine deficiency is the most prevalent in Asia, but pockets of deficiency exist in Africa, the Andes, and even Europe.

Vitamin A deficiency poses a threat to nearly 200 million children of preschool age as well as to hundreds of million older children and pregnant women. An estimated 14 million children under five have clinical signs of vitamin A deficiency (xeropthalmia) and perhaps 500000 young children become partially or totally blind each year as a result. Many of these children subsequently die, in part because of the frequent association of this deficiency with diarrhoea, respiratory disease, and other infections.

Anaemia stemming from inadequate intake of iron or low intestinal absorption of iron affects hundreds of millions of people, especially adult women and children under 13. Iron-deficiency anaemia can affect learning and work performance and may reduce resistance to infection. For pregnant women anaemia can be especially serious, as it increases the risk of haemorrhages or even congestive heart failure during labour and delivery.

Other micronutrient deficiency diseases of concern include pellagra (lack of niacin), scurvy (vitamin C), and beriberi (thiamin). Though much more rare than in the past, outbreaks of these diseases have occurred in recent years in a number of different refugee and famine situations. ${ }^{4}$

\section{Nutrient-depleting illness}

Even if food availability is adequate to meet nutritional needs, several types of illness may lower the absorption of nutrients within the body as well as affect food intake. These include diarrhoea, measles, and malaria and intestinal parasites such as giant roundworm, hookworm, and whipworm. The United Nations Children's

\footnotetext{
${ }^{4}$ Centers for Disease Control, 'Famine-affected, refugee, and displaced populations: recommendations for public health issues', Morbidity and Mortality Weekly Report, 41, RR-13, (24 July 1992) pp 1-76; Chen, R. S. 'Refugees and hunger', The Hunger Report: (1990); Chen, R. S. (gen. ed.) HR-90-1; Alan Shawn Feinstein World Hunger Program, Brown University, Providence, RI (1990) pp 49-70.
} 
Fund (UNICEF) estimates that diarrhoeal disease is the major cause of death for four million children under five annually. Acute diarrhoea typically results in short-term reductions in solid food intake, malabsorption of nutrients, and endogenous nutrient loss. Persistent diarrhoea (more than two weeks) can lead to severe growth faltering and other signs of nutritional deficiency. ${ }^{5}$

Measles is commonly associated with weight loss and growth faltering, poor food intake, malabsorption, and vitamin A deficiency. It also appears to suppress the immune system, allowing pneumonia, diarrhoea, croup, and other infections to take hold with consequent effects on nutritional status. UNICEF estimates that measles is the major cause of death for some 1.5 million young children each year and a contributing factor in many other child deaths.

Malaria kills an estimated one million children annually. Its most common nutritional consequence is anaemia and growth faltering. Other effects include low birth weight, neonatal anaemia, and immune suppression.

Intestinal parasites plague more than one billion people worldwide (see Table 1). They typically cause weight loss and anaemia and some species may also contribute to poor food intake, malabsorption, endogenous nutrient loss, and vitamin A deficiency. Deworming efforts have in many instances led to measurable improvements in nutritional status.

\section{0: a warmer, more crowded, connected, and diverse world}

The world of 2060 is less than a lifetime away and is likely to be experienced by up to half of those who today might be graduating from secondary school. We have chosen to examine the prospects of a food-secure world using such a long time frame because current scientific estimates project that by 2060 two major changes in the global situation will be fully evident. In the view of most demographers, the great demographic transition from a developing world with high births and high deaths to a world with low births and low deaths will be virtually complete by 2060 . And most atmospheric scientists expect to see by 2060 at least a doubling of greenhouse gases accompanied by significant changes in the world's climate.

It is difficult to sketch such a world in great detail but it may be helpful to contemplate an oceanographic metaphor. We might think of change over the next 66 years as currents, tides, and surges, undertows, and riptides. The currents are the long-term trends, the tides are the cyclical swings, and the surges, undertows, and riptides are the surprises.

We believe that the world of 2060 will be warmer and more crowded, more connected but more diverse. Environmental change, population growth, and increasing connectedness and diversity are powerful trends as deep-running as the great ocean currents, seemingly set in place with little possibility of reversal, although clearly subject to slower or more rapid movement. Unless there is some fatal flaw in present-day scientific understanding, we are already deeply committed to a warmer world. Recent scientific assessments suggest that a doubling of atmospheric carbon dioxide concentrations and other increases in trace gases will lead to an average temperature rise of $1.5-4.5^{\circ} \mathrm{C}$ with the potential for significant spatial and temporal variation from this mean (Houghton et al., 1992). Changes in

${ }^{5}$ Grant, J. P. The State of the World's Children (1991), United Nations Children's Fund, New York (1991); Tomkins, A. and Watkins, F. Malnutrition and Infection: A Review, ACC/SCN State-of-the-Art Series, Nutrition Policy Discussion Paper No 5, United Nations Administrative Committee on Coordination-Subcommittee on Nutrition (1989) 
precipitation, cloudiness, humidity, sea level, weather extremes, and other aspects of the environment could also result. In combination with other human-induced changes in local and regional environments, we foresee a worid environment in 2060 significantly different from that of today. The world of 2060 will have a population of at least 10 billion people. Expectations of future population growth have steadily increased as present trends toward lower fertility rates have siowed. By 2060 the proportion of population living in what is now considered the developing world will have grown from 77 per cent in 1990 to more than 85 per cent. More than half of the world's population will be living in urban areas, and the largest cities will likely grow into the tens of millions.

The world of 2060 will also be much more closely connected by ties of communication, economic production and consumption, interlinked technologies, and migration. Within the next few years, at least two and probably three major common-market, free-trade blocs are likely to emerge with associated blocs in the south. Hlows of goods, capital, and technology will most certainly be accompanied by flows of people. New information technologies and mass communication techniques will continue the trend towards faster, more intensive, and more inclusive flows of information, overcoming many different geographic, temporal, linguistic, cultural, and political barriers. It is not even clear that in 2060 countries will still be relevant units for calculating large-scale food security. Paradoxically, such connectedness will not necessarily homogenize the world's people beyond the ever present Coca-Cola, but may well increase the diversity of both people and things. Goods, information, and people are generally drawn to places of existing wealth or opportunity, which can make such places more diverse. And strong countercurrents that emphasize ethnic, national, and religious distinctiveness may create eddies and whirlpools where differing currents mix and clash. In contrast to the foregoing long-term trends, there are the more familiar cycles or tides that are superimposed on the great underlying currents. Many of these are short term such as the current recession of the business cycle or the so-called 'El Niño' phenomenon that affects the Pacific Ocean and environs at irregular intervals. Then there are decades-long swings. For example, in the great democracies, there may be recurrent swings towards the left or the right of the political spectrum. Over larger-time scales of 50 years, there are the so-called Kondratief cycles, based on the introduction of clusters of new technologies (e.g., textiles, steam, steel, petrochemicals, and electronics).

We are not at all confident where the world of 2060 will fall in the ebb and flow of these great tides. But we expect that such recent trends as those towards democracy or market economies which are often regarded as deep currents of change may well emerge as recurrent tides. We will probably not return to a bipolar world in the near future, but US dominance is already proving elusive. New configurations of economics and politics are already evolving. The infatuation with the market will diminish in some countries as the high social costs of inequity begin to outweigh the benefits of overall growth. What will replace the market is not certain. Some of the chaos, gridlock, and corruption of emerging democracies may encourage the re-emergence of authoritarian institutions or worse. Younger leaders now taking the place of the Cold War generation in positions of influence will in turn give way to a younger generation moulded by the beginning of a new century and new millennium.

Finally, we are least confident about the undertows, riptides, and storm surges that batter our conventional expectations, other than the wisdom of surely expecting surprises. National boundaries that had seemed immutable for decades 
have been swept away in a matter of months. These changes in turn have had repercussions around the world that may take years if not decades to play out in full. Coalitions and alliances formed in reaction to specific crises create new channels of communication and action that can deepen into new norms of human behaviour and interaction. Hidden or ignored undercurrents like the spread of AIDS can eat away at the foundations of society, increasing the potential for disaster and surprise.

\section{Towards 2060: a food-secure world}

Charting the confluence of these diverse phenomena and their implications for building a food-secure world during the next 66 years is at the least a monumental task. Instead, we propose four outcomes that might characterize such a world and speculate about how they might be attained. In the food-secure world of 2060 , famine will be an historic occurrence of the past, less than 1 per cent of the world's population would experience extremes of seasonal or chronic undernutrition, endemic micronutrient deficiencies would virtuaily disappear, and nutrientdepleting illness would be prevented or controlled. To move towards such a food-secure world requires a global implementation of food as a basic human right. Food supply would have to grow at rates as great as in the previous haif century. International and regional welfare systems will need to be institutionalized to provide for famine prevention, emergency assistance, maintenance and supplementation of entitlements, and special programmes addressed to the distinctive needs of women, children, and other groups vulnerable to hunger. And in a highly connected world of 2060 , there should be much interest in learning how to cope with surprise, to achieve resilience by maintaining flexibility.

\section{Food as a human right}

A food-secure world would be one in which food as a human right would be the norm of social behaviour, an expectation upheld and enforced by all and for all. The rudiments for the international recognition of a human right to food currently exists in the form of the Universal Declaration of Human Rights, the International Covenant on Economic, Social and Cultural Rights, and in conflict situations, the 1977 protocols to the Geneva Conventions of 1949. Yet in 1984, the foremost legal expert on rights to food could write:

Few human rights have been endorsed with such frequency, unanimity, or urgency as the right to food, yet probably no other human right has been as comprehensively and systematically violated on such a wide scale in recent decades (Alston, 1984).

Since then there has been a slow but marked improvement on the leading edge in the creation of such a social norm - the provision of humanitarian assistance. A human right to food by civilians in zones of armed conflict is gradually emerging as enforceable even within the borders of a civil conflict or against the wishes of host governments. Simply stated, there is growing agreement that no nation or governmental authority has the right to starve its own people. The transition to the case where all nations and peoples live up to their responsibilities to ensure that everyone is adequately fed will be long and difficult but has advanced considerably since 1984. Nevertheless, though war and conflict may themselves still persist, we are optimistic that by the middle of the next century the use of food as a weapon will be eliminated. 


\section{Sustainable food availability}

It is widely believed that there is actually plenty of food in the world and that hunger results mainly from its maldistribution. This is certainly true for a world universally content with a nutritionally adequate, but rather basic vegetarian diet. Distributed according to nutritional need, the vegetarian food supply plus the production from naturally grazed animals could support as much as 120 per cent of the world's current population. But for a world whose diet contains a modest amount of animal products derived from cereal grains, then there is only enough food produced at present to meet fully the nutritional needs of about three-quarters of the world's population. And to feed people with a healthy but animal-rich industrialized national diet, there would be only enough food for a little more than half of the world's population.

These figures do not necessarily imply that people cause hunger by eating cereal-based animal products or that there is or will be a global food shortage. Economists rightly point out that if poor countries and peoples had greater purchasing power then more food would be produced: the world has much unused capacity for producing food. And without such purchasing power, cereal products not used in animal feed would still not be available to poor people unless given away as food aid. Studies of the expenditures of poor people also show that with increased income, most poor people want to spend some of that income for a diverse diet that includes animal products except where restricted by religious preference.

All of the foregoing suggests that in a world of somewhat more than doubled population, food availability will have to increase three- to fourfold simply to meet the food requirements and modest expectations of improved diets of a food-secure world. Between 1934 and 1989, food production measured in terms of food calories grew by an average of 2.1 per cent per annum with per capita growth of about 0.6 per cent. For a fourfold increase in food production between 1990 and 2060 growth will have to be at a rate of 2 per cent per year, or about the historic average.

Can this historic rate of increasing food production be sustained to provide enough food for improved diets for a world with a doubled population? A key component of the scientific and policy arsenal for improving food supply is agricultural biotechnology. This array of molecular, cellular, and whole-plant biology techniques is applied to tailoring plants used in agriculture to resist pests, tolerate heat and drought, and respond more efficiently to nutrients and moisture. However, the first biotechnology products in the marketplace will probably benefit farmers in rich nations. Agricultural biotechnology is unlikely to contribute to the alleviation of hunger in developing nations during the coming decade. Continued progress into the next century will depend greatly on improved capabilities on the part of developing country scientists and farmers (Messer and Heywood, 1990).

Even if food production could be trebled or quadrupled, could it be sustained under the additional burdens of heightened soil and water loss, pesticide and fertilizer use, and changing climates that will accompany such increase? Our research suggests some important questions for an uncertain future, a number of which are considered in the papers to come. First, we must ask whether more food can be made available from existing agricultural production. The present global food system is not very efficient in transforming raw agricultural products into usable food (Chen, 1990; Bender, in press). Second, we need to examine alternatives for increasing food production in the light of their potential impacts on the global environment. For example, it may he necessary to weigh the benefits of 
bringing more cropland, irrigation, and rangeland into production and of using more fertilizers against their contributions to methane and nitrous oxide emissions and loss of biomass. Similarly, measures to prevent or delay global environmental change that affect energy use, water management, and forest practices could have important near-term effects on agricultural sustainability (Chen, 1990; Rosenberg and Scott, in press). Notably, the success of these measures in actually reducing or spreading out environmental changes is by no means guaranteed.

\section{Adequate household incorre}

Household income affects food security directly, providing the major source of entitlements for the food required by the household, income that is currently inadequate in households with a total population of more than 700 million. Indirectly, household incomes in the aggregate affect the size of the available food supply by virtue of its effects on encouraging greater production. This suggests that in a world of somewhat more than doubled population, household income will have to increase four to sixfold (depending on the pattern of income distribution) in order to meet the food requirements and modest expectations of improved diets of the poorest households. But increasing income is not enough. Although it is true that for the poorest households up to 85 per cent of income is spent on nutrition, it appears that in general a 10 per cent increase in income increases dietary calories only by 4-6 per cent (Marek, 1992). This occurs because some of the additional income is spent on non-food needs and some on greater and more costly food varieties. Thus for a food-secure world, even raising most households above the poverty level would still require a pervasive safety net.

\section{Safety net}

To have achieved a food-secure world will require a pervasive safety net just as such a welfare system is required in the wealthiest of countries today. Famine can be abolished because it is systematically anticipated, monitored and prevented. Natural and technological disasters will continue to require emergency assistance. Cycles of crop production, income, illness and family creation and loss will continue to generate the need for entitlement maintenance and supplementation. The special needs of women and children will have to be met by responsive maternal and child care systems.

Just how such a safety net would be created and supported in 2060 cannot be foreseen, as the very units of social organization required for implementation are in doubt. But the outlines of such systems can be foreseen, both in the prototypes now operating within many developing countries and the advanced systems in place in the wealthiest countries.

\section{Famine prevention}

Many of the tools needed to prevent famine are already in place. Efforts to cope with drought, flood, war and famine in the 1980s have led to major improvement in the global system for providing emergency food aid. A major international early warning system coordinated by the United Nations Food and Agriculture Organization was established in 1975 , and several regional systems are in operation as well. Recent efforts to improve understanding of the underlying vulnerability of particular groups to famine and to coordinate development, response, and relief efforts based on this understanding hold promise of more timely and effective interventions before famine conditions spread. 
The major obstacle to eliminating deaths due to famine remains the destruction or interdiction of civilian food supplies in zones of armed conflict. The 1977 protocols to the Geneva Conventions of 1949 that prohibits the starvation of civilians as a means of combat provide the rudiments for international protection of civilian rights to food. Ad hoc interventions in conflicts have had some success in staving off mass starvation, though not the occurrence of famine, as with most recent efforts to deliver food to civilian populations in Mozambique and the Sudan. At the moment such efforts are frustrated by the renewal of fierce post-Cold War political, ethriic, religious, and even clan-based rivalries and civil wars, as seen in Bosnia, Somalia, Liberia, Mozambique and Angola, and the Kurdish regions of Turkey, Iraq, and Iran. Ironically, while the international system seems almost overwhelmed at times with these renewed outbreaks, and European and African nations have failed in their collective regional responsibilities, there is also the opportunity for a major breakthrough in the standards of international conduct. We now have a series of precedents in which humanitarian concerns can overcome the barriers posed by national sovereignty if necessary to prevent famine. These precedents have by no means been universally applied, but they do provide a starting point for holding responsible parties to higher standards of behaviour.

\section{Emergency assistance}

The international community has distributed some 10-12 million metric tons (mmt) of food aid annually in recent years to developing countries. Of this total, some 2-4 mmt usually go to emergency situations, and an additional 1-2 mmt help to feed a growing number of refugees and other displaced peoples. Improved coordination between donor and recipient countries and international agencies is making it possible to place emergency stocks nearer to where they may be most useful and to deliver them when and where needed. The overall availability of food aid in the future will depend on a range of factors, including national agricultural and trade policies, world food markets, and international use of food aid as a tool for humanitarian assistance, socioeconomic development, and foreign policy. However, it is worth noting that current levels of food aid, which have remained relatively stagnant in recent years, are far lower than the projected $20-60 \mathrm{mmt}$ needed in this decade both to provide emergency assistance and to stabilize food prices in developing countries. ${ }^{\circ}$

Many problems do remain in emergency assistance efforts, especially when 'human' disasters like war and political oppression strike. In developing countries, local capacity to assist those in need in times of disaster is often limited not by concern but by resources. International responses to such disasters are frequently haphazard, delayed, and at times counterproductive, as evidenced by the varied assistance given to refugees and returnees during the recent Persian Gulf War. ${ }^{7}$

\footnotetext{
${ }^{6}$ Board on Science and Technology for International Development, Food Aid Projections for the Decade of the 1990s, National Academy Press, Washington, DC (1989); also see Bender, W. H. 'Food aid and hunger', The Hunger Report: 1990, Chen, R. S. (gen. ed.) HR-90-1, Alan Shawn Fcinstein World Hunger Program, Brown University, Providence, RI, 1990, pp 49-70

${ }^{7}$ US Committee for Refugees, Mass Exodus: Iraqi Refugees in Iran, Issue Brief, US Committee for Refugees, Washington, DC (July 1991); Minear, L., Chelliah, U. B. P. Crisp, J., MacKinlay, J. and Weiss, T. G. 'United Nations coordination of the international humanitarian response to the Gult Crisis 1990-1992', Occasional Paper 13, Institute for International Studies, Brown University, Providence, RI (1992); Chen, R. S. 'Hunger among refugees and other people displaced across borders', Hunger 1993: Third Annual Report on the State of World Hunger-Uprooted People, Bread for the World Institute on Hunger and Development, Washington, DC (1992) pp 15-36.
} 
Nevertheless, there appears to be a slow but steady improvement in the logistical, institutional, and legal capabilities to deal with complex humanitarian situations. Whether this trend will be reversed by the burgeoning number of refugees and other displaced persons around the world and the unwillingness of developed nations to accommodate them remains to be seen.

\section{Entitlement maintenance}

Various systems to subsidize or distribute food or their income equivalents are at least as old as the Roman empire. While costly as a general entitlement, they can be quite effective when targeted to the truly needy. Especially effective are those that utilize existing markets to distribute fond through fond stamps, ration shops, or specially subsidized foods. Supplementary rural food entitlement is more difficult because it is harder to reach rural households on a sustained basis with food-welfare programmes. But there is some successful experience in combining income opportunities in the countryside and efforts to increase agricultural productivity by providing wage and food income in return for labour to construct needed agricultural infrastructure and restore environmental resources. Income diversity can also help the food poor. Thus, programmes like the Grameen Bank in Bangladesh that provide self-sustaining sources of credit to start small businesses or to produce handicrafts and services have proven very effective, especially for women. Efforts of this kind can also help to reduce the burden of seasonal hunger imposed by heavy reliance on agriculture. Food-poor households that raise their own food have to cope with the deterioration of their natural resources, the loss of crucial access to common resources, and restriction to all but the most ecologically marginal land. For the self-provisioning population, maintaining access to the natural resource base and the inputs needed for agriculture, herding, or fishing is becoming increasingly difficult in the face of growing population and increased competition for land. There are important opportunities for redistribution to smallholders of land that is little used and a variety of low-cost techniques that have demonstrated ability to sustain productivity, provide fuelwood, limited soil erosion, and increase food and income. However, it seems likely that the developing countries will have to follow the path of the developed countries in providing subsidies and basic entitlements to their rural populations in order to stem the flow of population into urban areas and retain a viable agricultural economy.

\section{Special needs programmes}

Immunization and low-cost treatment of diarrhoea, malaria and measles promise to reduce the impact of disease on nutrition for most young children even as early as the end of this century. But such systems needed to be maintained and even wealthy countries such as the United States find growing numbers of children without immunization in the absence of continuous programmes focused on the poor and the needy. Sustained breastfeeding, expanded supplemental feeding, and growth monitoring, in combination with limiting the effects of childhood illness and undernutrition, could eliminate the common forms of childhood wasting and stunting. The prevalence of breastfeeding is stable or even increasing in many developing countries, possibly as a result of continuing efforts to encourage and maintain breastfeeding. Anaemia, especially among pregnant women, is particularly troublesome as it requires regular iron supplementation. All of these activities breaking the disease-nutrition nexus and meeting the special dietary needs of women and children - can be handled well within the context of effective low-cost 
systems of maternal and child health care supported by adequate nutrition education.

Reducing the burdens imposed by intestinal parasites on two billion or more people will not be an easy task. Ongoing clinical trials of deworming drugs suggest that a near-term public health solution is possible at least for those most severely affected. In the long run, however, improvements in sanitation and safe drinking water are critical. The pace of improvements will likely depend on financial, institutional, and technological developments in the rapidly growing cities, densely populated watersheds, and environmentally threatened rural areas of the future.

\section{Adaptations to surprise}

To achieve a food-secure world by 2060 , societies will have successfully adapted to a series of unexpected surprises. These will have made the task easier and harder, and certainly different than it might have been. The surprises themselves are by definition unpredictable, but the mechanisms are easily imaginable. For example, one can readily conceive of a new disease outbreak that would seriously disrupt plant or animal production at the same time that new breakthroughs in biotechnology begin to provide substantial improvements in yields and nutrition. New and unexpected sources of conflict may well interfere with the flow of food, people, and caring, while social and religious movements enhance the development of global responsibility. Optimistic outlooks in some regions will undoubtedly give way to pessimism but perhaps a few of today's 'basket cases' will confound the conventional wisdom.

To achieve food security in the world of 2060 will require a capacity to deal with surprise - to take advantage of surprising opportunities and to maintain social and technical flexibility to cope with surprising adversity. Such a capacity could entail the maintenance of large food stocks and other emergency response resources to cope with fluctuations in food production due to a changing climate or the weather extremes associated with a volcanic eruption of the magnitude of the Tambora eruption in 1715 . It will certainly require support for the research and development infrastructure to provide continuing improvements in food production in the face of a variable environment and ongoing population change. And though the details are hard to foresee, it will need to include a safety net to ensure that the most vulnerable people and regions are not caught unprepared.

\section{Scenarios for 2060}

Our scenario of a food-secure world in 2060 thus incorporates a multidimensional, normative view of future food security based upon trends and prospects in agriculture, economy, technology and social development. A world without famine must not only have plenty of food, but also a widespread recognition of the human right to food and effective mechanisms to prevent famine and alleviate its root causes. A world with relatively low levels of undernutrition must not only be more wealthy, but also willing and able to provide food entitlements to poor and vulnerable groups as needed. A world with virtually no micronutrient deficiencies and nutrient-depleting illness must not only have more diverse diets, but also the income to support widespread access to adequate sanitation, safe water, public health and primary care services, and nutritional and health education.

How does our normative scenario compare with other views of future food security? There are at least two other research communities that have attempted to 
address long-term food security issues: first, economists, agriculturalists, and others concerned with the future supply and demand for food in relationship to population growth, technological change, and self-sufficiency and trade; and second, those involved in assessing climate change and its implications for agricultural systems. It would thus be instructive to examine future scenarios of 2060 based on: (1) 'conventional' expectations of future food supply and demand and trends in agricultural and economic systems; and (2) a world affected by a changing climate.

Fortunately, we are able to draw on the recent work of Fischer et al. (1994) utilizing the Basic Linked System (BLS) of the International Institute for Applied Systems Analysis (IIASA). The BLS is a general equilibrium system of agricultural policy models that are linked through trade, world market prices, and tinancial flows. It presently consists of a mix of some 35 different country and country-group models each designed to simulate the overall national or regional economy with particular attention to the agricultural sector. These individual models allow for evolutionary changes in capital investment and labour flows within and between the agricultural and non-agricultural sectors and for technical progress (though not induced innovation).

The BLS was used to generate a 'reference' scenario for the year 2060 by integrating the model in annual time steps with population growth, labour force participation, and technological change as the main exogenous inputs. Growth in Gross Domestic Production (GDP) is computed endogenously. The reference scenario projects that GDP will increase by a factor of 4.4 over 1980 levels by 2060 . Total cereal production increases by a factor of 2.25 over this period, barely keeping up with population growth. Assuming no change in income distribution, the BLS projects that the number of undernourished (computed according to the older FAO methodology) will rise from 501 million in 1980 to 641 million in 2060 . This represents a significant decline in the proportion of undernourished, from 23 per cent to 9 per cent. As it is primarily an economic model system, the BLS makes no projections about famine, micronutrients deficiencies, or nutrient-depleting illness. It says nothing explicit about recognition of the human right to food, safety nets, and adaptability to surprise.

A second set of scenarios was created to test the sensitivity of the BLS to a changing climate. Synthetic time series of temperature and precipitation for individual GCM grid squares were generated by combining the results of three different general circulation model (GCM) simulations under conditions of doubled atmospheric concentrations of carbon dioxide $\left(\mathrm{CO}_{2}\right)$ with observed climatic data. These time series were then used as inputs into crop models for wheat, maize, rice, and soybeans applied to more than 100 sites in 18 countries. The crop models take into account the effects of higher $\mathrm{CO}_{2}$ concentrations on plant growth and water use and allow changes in management practices, e.g., in response to a changing climate, to be tested. The resulting yield changes for three sets of GCM runs and four different cases (with and without the $\mathrm{CO}_{2}$ fertilization effect and with two levels of adaptation) were aggregated regionally and nationally and used as inputs into the BLS.

In all cases, climate change leads to net declines in cereal production and agricultural GDP in the developing world. Modest increases in production in the developed world in most instances do not fully counterbalance the developing world declines, except at high levels of adaptation in the less dramatic GCM scenarios. World market prices increase at the same time that developing countries are forced to import more cereals. As a result, the estimated number of 
Table 2. Scenarios of food security in $\mathbf{2 0 6 0}$

\begin{tabular}{|c|c|c|c|}
\hline Dimension of hunger & $\begin{array}{l}\text { Food-secure } \\
\text { scenario }\end{array}$ & $\begin{array}{l}\text { BLS } \\
\text { reference } \\
\text { scenario }\end{array}$ & $\begin{array}{l}12 \text { Climate } \\
\text { change } \\
\text { scenarios }\end{array}$ \\
\hline Famine & None & $?$ & $?$ \\
\hline \multicolumn{4}{|l|}{ Undernutrition (chronic and seasonal) } \\
\hline FAO food poverty (1.2 BMR) & $<100$ million & 641 million & 629-2087 million \\
\hline Micronutrients deficiencies & Virtually none & $?$ & $?$ \\
\hline Nutrient-depleting illness & Controlled & $?$ & $?$ \\
\hline
\end{tabular}

undernourished people is projected to increase in 11 of the 12 clinate change scenarios examined.

Tables 2 and 3 summarize the results of the BLS scenario experiments in comparison with our scenario of a food-secure world. These illustrate that there is a large gap between a 'desirable' food-secure scenario and the BLS scenarios with respect to the prevalence of undernutrition and future growth in food availability and income. About 500 million more people, or an additional 5 per cent of the world people in 2060, suffer from severe undernutrition in the BLS Reference Scenario compared with the food-secure scenario. Under the most adverse climate changes considered, the number of undernourished could increase drastically to more than two billion, or 20 per cent of the 2060 population. These higher numbers stem in part from the much lower growth in food availability and income projected to occur in the BLS scenarios.

\section{Scenario assumptions}

It is useful to review the differing assumptions embedded in these scenarios (Table 4). Both sets of scenarios utilize similar projections of population; and both allow for the persistence of poverty, but in the food-secure scenario, there is room for changes in income distribution, whereas in the BLS scenarios income distribution is fixed. Both foresee greater global economic integration, but only the food-secure scenario allows for substantial dietary change. By intent, the BLS Reference Scenario posits no drastic changes and the climate change scenarios allow only for changes in climate and carbon dioxide levels. Both sets of scenarios allow for technological change, but in the BLS scenarios this is represented as a slow but steady growth in yields whereas the food-secure scenario may well require substantial technological improvements in most developing countries. Of course, we must reiterate here that the food-secure scenario is purely normative and

Table 3. Requirements for achieving scenario level of food security

\begin{tabular}{|c|c|c|c|}
\hline Requirements & $\begin{array}{l}\text { Food-secure } \\
\text { scenario }\end{array}$ & $\begin{array}{l}\text { BLS } \\
\text { reference } \\
\text { scenario }\end{array}$ & $\begin{array}{l}12 \text { Climate } \\
\text { change } \\
\text { scenarios }\end{array}$ \\
\hline $\begin{array}{l}\text { Food as a basic human right, not a } \\
\text { weapon of war }\end{array}$ & $\begin{array}{l}\text { Recognized } \\
\text { by all }\end{array}$ & $?$ & $?$ \\
\hline Sustainable food availability & $3-4 \times$ higher & $1.9 \times$ higher & $1.5-2.1 \times$ higher \\
\hline Income growth & $4-6 \times$ higher & $3.3 \times$ higher & \\
\hline Safety net & Pervasive & $?$ & $?$ \\
\hline Ability to cope with surprise & & & \\
\hline
\end{tabular}

\footnotetext{
a Adjusted to the $1990-2060$ period.
} 
Table 4. Major assumptions in achieving scenario level of food security

\begin{tabular}{|c|c|c|c|}
\hline Key assumptions & $\begin{array}{l}\text { Food-secure } \\
\text { scenario }\end{array}$ & $\begin{array}{l}\text { BLS } \\
\text { reference } \\
\text { scenario }\end{array}$ & $\begin{array}{l}12 \text { Climate } \\
\text { change } \\
\text { scenarios }\end{array}$ \\
\hline Population increase & $-2 \times$ higher & $-2 \times$ higher & $-2 \times$ higher \\
\hline Dietary change & More diverse & $?$ & $?$ \\
\hline Income distribution & Changeable & Fixed & Fixed \\
\hline Relative poverty & Persists & Persists & Persists \\
\hline Economic integration & Increases & Increases & Increases \\
\hline Surprises & Continue & $\begin{array}{l}\text { "No drastic } \\
\text { changes" }\end{array}$ & $\begin{array}{l}\text { Mean climate } \\
\text { change only }\end{array}$ \\
\hline
\end{tabular}

speculative, i.e., it addresses the question of what targets might have to be met if food security is to be achieved and maintained by 2060 . The BLS scenarios project from the present in an effort to assess plausible future conditions with and without climate change. Comparison of these two approaches illustrate the potential difference in magnitude between 'business as usual' and what we pose as a desirable outcome. This comparison thus sets an agenda for thinking about the feasibility and multi-dimensionality of a future food-secure world.

\section{Conclusion: an agenda for future food security}

In our efforts to assess world food security in the next century, it will be important to look beyond changes in the world's capacity to produce food given the risk of possible climate changes. We argue here for a broader notion of food security, one that considers food availability and access at a range of levels in ways that support the activity, health and development of all human beings. Such an expanded notion of food security raises the standards by which we can judge success in food security, but it also offers multiple pathways for achieving it. Not only can we attempt to increase the overall supply of food, but we can and should address questions of income distribution, dietary needs, and food losses and waste. Efforts to promote individual food security through better health and nutrition education will complement efforts to ensure greater entitlements to food at individual, household, and regional levels. Strengthening emergency response capabilities and other aspects of societal safety nets will help to reduce pockets of food insecurity as well as to improve overall resilience in the face of change and surprise.

There is little doubt that the overall 'delivered' supply of food must increase to meet the combined needs of both population growth and improved diets. In the long run, such growth need only match that of the past 50 years, if population 'only' doubles during the next 66 years. Some of this growth could come from more efficient utilization of food production. Still, ongoing debates about the sustainability of the historic growth rates do call into question the feasibility of such continued growth, especially in the face of possible climate change. Were this level of growth not to be achieved, attainment of a truly food-secure world would certainly become much more difficult. And even with the greater levels of food availability and access herein proposed - increases of three to four times in food production and four to six in income - achieving food security will require major strengthening of human right to food, a greatly expanded safety net, and an increasing capability to adapt to surprise. Fortunately, the rudiments for value changes, social institutions, and increased flexibility can already be found. With nurturing (and perhaps a dose 
of optimism) it seems possible that these could serve as the basis for building the food-secure world of the future. Many of those concerned about climate change assume that a changing climate will make the task of achieving greater food security much more difficult. Changes in temperature, precipitation, cloudiness, sea level, and other aspects of climate, if they do occur, seem likely to disrupt growth in food production and income. Measures to mitigate or adapt to climate change may also inhibit production growth or divert income from efforts to alleviate poverty or food insecurity. But we also can conceive of ways in which the confluence of efforts to adapt to climate change and the effort to achieve food security can be mutually reinforcing in beneficial ways. First, those who presently have the least food security are concentrated in South Asia and Africa, where some scenarios of regional climate change suggest that there could be improvements in growing conditions. It may be possible for these areas to take advantage of these better growing conditions as they intensively develop their agricultural infrastructure in coming decades. Second, the global nature of the climate change threat reinforces inclinations towards international responsibility and solidarity. Indeed, bargaining between developed and developing nations on potential preventive and adaptive measures could highlight the achievement of food security as a relatively low-cost objective with high payoff in terms of enhancing international cooperation and building adaptive capabilities. Finally, achieving food security for both developed and developing countries in an uncertain and changing climate will likely require the establishment of responsive policies, programmes, and institutions that could benefit the rich and poor alike.

Our vision of a food-secure world in the year 2060 is clearly based on a high degree of speculation - and perhaps unfounded optimism. Nevertheless, we argue that such a normative vision can help to widen perspectives on the interactions between future food security and global climate change in ways that can encourage creative thinking about how to transform new possibilities - and threats - into beneficial opportunities. In today's food insecure world, darkened by the spectre of unprecedented anthropogenic changes in the environment, such creative thinkng may be our best defence.

\section{References}

Alston, P (1984) 'International law and the right to food', Food as a Human Right, Eide, A et al. (eds) United Nations University, Tokyo, p 152

Bender, W H (1994) 'An end use analysis of global food requirements', Food Policy (in press)

Chen, R S (1990) 'Global agriculture, environment, and hunger: past present, and future links', Environmental Impact Assessment Review, 10 (December 1990) pp 335-358

Fischer, G, Frohberg, K, Parry, M and Rosenzweig, C (1994) 'Climate change and world food supply, demand and trade: who benefits, who loses?', Global Environmental Change (in press)

Houghton, J T, Callander, B A and Varney, S K (eds) (1992) Climate Change 1992: The Supplementary Report to the IPCC Scientific Assessment, Cambridge University Press, Cambridge, UK

Marek, T (1992) 'Ending malnutrition: why increasing income is not enough, population, health, and nutrition division', Technical Working Paper No 5, Afriea Technical Department, The World Bank, Washington, DC

Messer, E and Heywood, P (1990) 'Trying technology: ncither sure nor soon', Food Policy, 15 (August) pp $336-345$

Rosenberg, N J and Scott, M J (1994) 'Implications of policies to prevent climate change for future food security', Global Environmental Change (March) (in prcss)

Sen, A K (1981) Poverty and Famines: An Essay on Entitlement and Deprivation, Clarendon Press, Oxford

World Bank, Poverty and Hunger: Issues and Options for Food Security in Developing Countries (1986) The World Bank, Washington, DC 